\title{
NECESSIDADES PSICOLÓGICAS BÁSICAS: DEFINIÇÕES OPERACIONAIS NA DOCÊNCIA UNIVERSITÁRIA
}

\author{
BASIC PSYCHOLOGICAL NEEDS: \\ OPERATIONAL DEFINITIONS IN HIGHER EDUCATION TEACHING
}

NECESIDADES PSICOLÓGICAS BÁSICAS:
DEFINICIONES QUE OPERAN EN LA DOCENCIA UNIVERSITARIA

Tarcia Rita Davoglio ${ }^{1}$

Jordana Wruck Timm ${ }^{2}$

Bettina Steren dos Santos ${ }^{3}$

Fernanda de Brito Kulmann Conzatti ${ }^{4}$

\begin{abstract}
RESUMO
A Self-Determination Theory (SDT) pressupõe que a qualidade autônoma da motivação resulta da interação equilibrada entre demandas internas do self e nutrientes contextuais, a partir da satisfação das necessidades psicológicas básicas (NPB) de autonomia, competência e pertencimento. Este estudo qualitativo teve por objetivo explorar as definições operacionais das NPB no âmbito da docência na Educação Superior. Para tanto, a amostra de professores universitários respondeu, de forma anônima e voluntária, a três questões abertas abordando a temática, analisadas por meio da Análise Textual Discursiva. Como resultado, emergiram sete descritores operacionais para definir Autonomia, além de uma subcategoria crítica; sete para Competência e cinco para Pertencimento, detalhados e debatidos em consonância à docência. Embora circunscritos a uma amostra, são resultados potencialmente relevantes para subsidiar a compreensão e os avanços no campo motivacional, bem como para a promoção de políticas voltadas à satisfação e ao bem-estar psicológico do profissional docente da Educação Superior.
\end{abstract}

PALAVRAS-CHAVE: Educação Superior. Docentes. Motivação. Necessidades Psicológicas Básicas.

\footnotetext{
${ }^{1}$ Doutora em Psicologia - Pontifícia Universidade Católica (PUC) Porto Alegre, RS - Brasil. Professora colaboradora - Pontifícia Universidade Católica (PUCRS) Porto Alegre, RS - Brasil.

E-mail: tarcia.davoglio@pucrs.br

${ }^{2}$ Doutoranda em Educação - Pontifícia Universidade Católica (PUC) Porto Alegre, RS - Brasil. Bolsista CAPES.

E-mail: jordanawruck@hotmail.com.

${ }^{3}$ Pós-doutora em Educação - The University of Texas at Austin (UTAustin). Doutora em Psicologia -

Universidade de Buffalo (UB). Professora permanente - Pontifícia Universidade Católica (PUC) - Porto Alegre, RS - Brasil. E-mail: bettina@pucrs.br

${ }^{4}$ Mestre em Educação - Pontifícia Universidade Católica (PUC) - Porto Alegre, RS - Brasil.

E-mail: nandakulmann@gmail.com
}

Submetido em: 04/04/2016 - Aceito em: 11/07/2016

\section{(C) ETD-Educação Temática Digital Campinas, SP v.19 n.2 p. 510-531 abr./jun. 2017}




\section{ABSTRACT}

Self-Determination Theory (SDT) maintains that the autonomous quality of motivation results from the balanced interaction between internal demands of the self and contextual nutrients from the satisfaction of basic psychological needs (NPB) of autonomy, competence and relatedness. This qualitative study aims to explore the operational definitions of NPB in the context of teaching in Higher Education. For this purpose, a sample of higher education academics answered, anonymously and voluntarily, three open questions, which analyzed by Discursive Textual Analysis. As a result, seven operational descriptors emerged defining autonomy, as well as a critical subcategory; seven of these are for competence and five for relatedness, which are discussed in detail and in relation to teaching in Higher Education. Although confined to a single sample, results are potentially relevant for our understanding and advances in the field of motivational as well as for the promotion of policies focusing on satisfying and meeting the psychological well-being of Higher Education faculty members.

KEYWORDS: Education. Faculty member. Motivation. Basic Psychological Needs.

RESUMEN: La Self-Determination Theory (SDT) asume que la calidad autónoma de la motivación resulta de la interacción equilibrada entre las demandas internas de lo self y los nutrientes del contexto, a partir de la satisfacción de las necesidades psicológicas básicas (NPB) de autonomía, competencia y pertenencia. Este estudio cualitativo tuvo como objetivo explorar las definiciones operativas de las NPB en el contexto de la enseñanza en la Educación Superior. Por lo tanto, la muestra de profesores universitarios respondió, de forma anónima y voluntaria, a tres preguntas abiertas que tratan el tema, analizadas mediante Análisis Textual Discursiva. Como resultado, surgió siete descriptores operativos para definir la Autonomía, así como una subcategoría crítica; siete para la Competencia y cinco por Perteneciente, detallado y debatido en consonancia a la enseñanza. Aunque restringidos a una muestra, son resultados potencialmente relevantes para subsidiar la comprensión y avances en el campo de motivación, así como para la promoción de políticas enfocadas en la satisfacción y con el bienestar psicológico del profesional de la enseñanza de la Educación Superior.

PALABRAS CLAVE: Educación Superior. Profesores. Motivación. Necesidades Psicológicas Básicas.

\section{INTRODUÇÃO}

No Brasil, especialmente nas últimas duas décadas, o debate e a produção de conhecimento sobre a docência universitária ganhou vigor (MOROSINI 2000; SOARES; CUNHA, 2010). Nesse cenário, as habilidades técnica e didática, até então tidas como definidoras na seleção de professores, vem deixando de ter primazia e muitas outras competências e habilidades passaram a ser demandadas, juntamente com a prerrogativa da uma nova visão da profissão docente (CAMPOS, 2007) e da expansão e internacionalização da Educação Superior, pondo em cena a diversidade e heterogeneidade de perfis docentes, cada vez mais responsáveis por se manterem motivados na carreira.

Diversos estudos tentam conceituar e especificar a motivação docente (por exemplo, SANTOS; RODENBUSCH; ANTUNES, 2009; JESUS; SANTOS, 2004), embora esta ainda demande maior relevância nos estudos acadêmicos, inclusive no âmbito internacional (VISEU et al., 2015). Compreender a motivação humana envolve certa complexidade, sendo

\section{(C) ETD-Educação Temática Digital Campinas, SP v.19 n.2 p. 510-531 abr./jun. 2017}


cada vez mais valorizada a qualidade motivacional relacionada à autodeterminação do sujeito frente ao contexto. Seguindo essa perspectiva, a motivação é tratada como um processo, no qual professores motivados intrinsecamente para a carreira docente potencializam sua prática educativa e seu engajamento profissional, ao mesmo tempo em que promovem em seus educandos a motivação autônoma para a aprendizagem.

Entre as teorias contemporâneas que podem subsidiar o estudo da motivação docente destaca-se a Self-Determination Theory (SDT) (DECl; RYAN, 2000; 2008a), a qual entende que há elementos tanto intrínsecos (interesses, crenças e escolhas próprias) como extrínsecos (pressões externas e resultados esperados) ao self agindo sobre a vontade e a determinação para as ações. Para a SDT, quanto mais as escolhas e comportamentos da pessoa se apoiam em elementos intrínsecos e na integração de princípios contextuais (extrínsecos) ao próprio sistema de valores mais a motivação assume caráter autônomo ou autodeterminado, o qual representa a base para a satisfação e o bem-estar psicológico.

Entre seus pressupostos fundantes, a SDT sustenta que o estudo sobre a motivação autodeterminada demanda pela consideração às necessidades psicológicas básicas (NPB), definidas como necessidades inatas e universais, cuja satisfação é essencial para o bemestar e o desenvolvimento saudável (DECl; RYAN, 2000). Postula que existem três NPB, agrupadas no senso de autonomia, no senso de competência e no senso de pertencimento (RYAN; DECl, 2002). O senso de autonomia se refere à flexibilidade e sensação de independência para agir de acordo com os próprios princípios, diante da integração de valores contextuais ao self, aprovados internamente. O senso de competência diz respeito à necessidade de se sentir eficaz em causar ou obter resultados desejáveis e evitar resultados indesejáveis em ações que envolvem diferentes níveis de dificuldade, evidenciando o reconhecimento pelo sujeito das próprias capacidades e recursos. O senso de pertencimento/afiliação, por sua vez, tem seu foco na necessidade do sujeito se sentir conectado e apoiado por outras pessoas com quem convive, tendo a percepção de estar integrado e pertencente aquele contexto (RYAN; DECI, 2002).

De acordo com a SDT, as NPB são interdependentes entre si, cuja satisfação concomitante ao longo do tempo está na origem do funcionamento motivado de modo autônomo, refletindo a sintonia entre interesses, vontades e ações e as demandas do meio externo. A frustração persistente de uma ou mais delas impacta sobre a motivação de modo negativo, sendo responsável pelas diferenças individuais no nível e na qualidade da motivação (DECY; RYAN, 2008a). Com isso, em grande parte, o ambiente social se

\section{(c) ETD-Educação Temática Digital Campinas, SP v.19 n.2 p.510-531 abr./jun. 2017}


caracteriza como uma fonte de "nutrientes" que irão ou não dar suporte à satisfação das NPB (RYAN; DECI, 2002; DECl; RYAN, 2008a).

Porém, ainda que as três NPB representem necessidades psicológicas típicas da natureza humana e promotoras de desenvolvimento saudável (RYAN; DECl, 2002; DECl, RYAN, 2008a; 2008b), podem ser expressas de modo variável, de acordo com a cultura e o ambiente social, o que significa que os nutrientes ambientais, que dão suporte a sua satisfação não possuem um padrão único. Em outras palavras, a definição operacional do que leva à satisfação de cada uma das NPB está intimamente relacionada ao contexto onde o sujeito se insere e em relação ao qual estabelece trocas e expectativa, sendo que este contexto influencia os níveis de autodeterminação.

A partir da SDT, entendemos que o reconhecimento das definições operacionais das NPB torna-se fundamental para a compreensão dos processos motivacionais docentes. A definição ou descrição operacional de um conceito teórico é dada pelas ações ou comportamentos manifestos que representam um conceito abstrato, possíveis de realização pelo sujeito (PASQUALI, 2010). Ou seja, para os professores universitários, quais elementos observáveis são utilizados para identificar a satisfação ou frustração das necessidades psicológicas de autonomia, competência e pertencimento em relação à profissão docente? A partir dessa questão norteadora, este estudo teve por objetivo principal explorar as definições operacionais das NPB de autonomia, competência e pertencimento, na perspectiva da SDT, em uma amostra de professores universitários. Mais especificamente, visou identificar e analisar, por meio da Análise Textual Discursiva (ATD), os elementos emergentes indicadores de satisfação dessas três necessidades no exercício da profissão docente, a partir da narrativa dos professores universitários pesquisados.

\section{PERCURSO METODOLÓGICO}

Os sujeitos desse estudo qualitativo exploratório foram 26 professores universitários, com idades entre 29 e 63 anos. O pré-requisito para a inclusão no estudo era estar ativo, com funções em sala de aula.

Os professores foram convidados a participar da pesquisa, voluntária e anonimamente, respondendo de forma presencial a três questões abertas, uma sobre cada NPB, em relação à profissão docente. Antes, porém, atendendo aos protocolos éticos referentes à pesquisa com seres humanos, os sujeitos foram informados dos objetivos do

\section{(C) ETD-Educação Temática Digital Campinas, SP v.19 n.2 p.510-531 abr./jun. 2017}


estudo e de sua implicação no mesmo e aqueles que aceitaram participar assinaram o Termo de Consentimento Livre e Esclarecido (TCLE).

A análise dos registros das respostas de cada participante foi realizada a partir da Análise Textual Discursiva - ATD (MORAES; GALIAZZI, 2011). A ATD tem como objetivo buscar diferentes leituras e releituras do fenômeno investigado, valorizando, sempre, a perspectiva e o olhar dos sujeitos. Esse método de análise utiliza as categorias como forma de focalizar o todo por meio das partes, sendo considerado um processo auto-organizado de produção de novas compreensões em relação aos fenômenos que se examina, de acordo com as seguintes etapas: (1) desmontagem dos textos, (2) estabelecimento de relações, (3) captação do novo emergente e (4) processo de auto-organização textual. Segundo os autores, quando se conhece a priori os temas da análise, separam-se as unidades de sentido de acordo com mesmos, neste caso, o senso de autonomia, de competência e de pertencimento.

Assim, a partir do contato com o corpus de análise partiu-se para a sua desconstrução e sua unitarização, considerando as três grandes categorias determinadas à priori. Na etapa do estabelecimento de relações, as unidades identificadas foram agrupadas a partir dos elementos que possuíam significados comuns, constituindo as subcategorias. Com a captação do emergente ocorre a finalização da composição das categorias, iniciandose um novo ciclo: o estabelecimento das relações entre as próprias categorias e subcategorias, produzindo o metatexto. Essa última etapa é um processo de autoorganização, no qual a emergência de novas compreensões é comunicada mediante os metatextos, representando um modo de teorização sobre o fenômeno investigado, a partir da teoria que o explora.

\section{RESULTADOS E DISCUSSÃO}

Os dados sociodemográficos coletados evidenciaram que os sujeitos da pesquisa formavam um grupo heterogêneo quanto à idade e funções exercidas na docência, passível de representar diferentes visões sobre as NPB, o que entendemos ser positivo por ampliar o leque de definições operacionais emergentes. A idade média dos 26 professores entrevistados foi de 45 anos e 5 meses ( $D P=9,0$ ), variando de 29 a 63 anos. Quanto a titulação acadêmica dezoito eram mestres, sete eram doutores e apenas um professor era especialista. A maioria possuía vínculo de dedicação exclusiva à carreira docente em Instituições de Ensino Superior (IES) privadas, atuava na profissão docente há mais de 15

\section{(C) ETD-Educação Temática Digital Campinas, SP v.19 n.2 p.510-531 abr./jun. 2017}


anos, exercendo diversas funções/atividades acadêmicas agrupadas sob o tripé ensino/pesquisa/extensão, inclusive algumas de caráter burocrático/gestão, corroborando a tendência de acúmulo de funções observada na Educação Superior, especialmente presente no ensino privado, já apontada na literatura (BIANCHETTI; MACHADO, 2013).

A partir da narrativa desses professores universitários, com base na ATD, emergiram sete subcategorias para definir operacionalmente o que os professores entendem como elementos de satisfação do senso de autonomia, além de uma subcategoria crítica à autonomia na docência. Emergiram sete subcategorias que definiram os elementos de satisfação do senso de competência e cinco subcategorias que definiram aqueles relacionados ao senso de pertencimento, conforme mostra a Figura 1. Porém, salientamos que para as NBP promovam a motivação intrínseca e autônoma, responsável pelo comportamento regulado pelo próprio self do sujeito, é necessário que estejam satisfeitas de forma concomitante em um dado contexto, em um nível mínimo pelo menos. Há, portanto, uma forte interdependência entre a autonomia, a competência e o pertencimento, o que determina essa demanda por satisfação conjunta para ter efeitos positivos sobre a motivação (DECl; RYAN, 2008a; 2008b). As setas internas na Figura 1 assinalam essa inter-relação das NBP e os colchetes apontam para o somatório das três NPB, tendo a motivação autônoma como resultado final dessa "equação" ${ }^{i}$. O equilíbrio entre a satisfação das NPB e a presença de motivação autônoma é o que propõem a SDT. 
- Direcionamento da própria carreira/desafios

- (Re) Construção de saberes

- Compartilhamento de experiências com pares

- Flexibilidade do planejamento pedagógicos e dos horários de trabalho

- Gestão institucional participativa

- Identidade/competência profissional consolidada

- Atuação em sala de aula

"Autonomia ilusória"

- Interesse, participação e aprendizagem dos alunos

- Desempenho dos alunos

- Recebimento de feedback positivo

- Reconhecimento pelos alunos, pares e instituição

- Qualificação e formação continuada

- Domínio do conteúdo e Experiência teórico-prática

- Gosto pela docência

- Reconhecimento pessoal e institucional

- Participação ativa em processos decisórios e em atividades conjuntas

- Convivência social com pares e aceitação de ideias, sentimentos e dúvidas

- Condições de trabalho compatíveis

- Desenvolvimento de atividades acadêmicas de qualidade

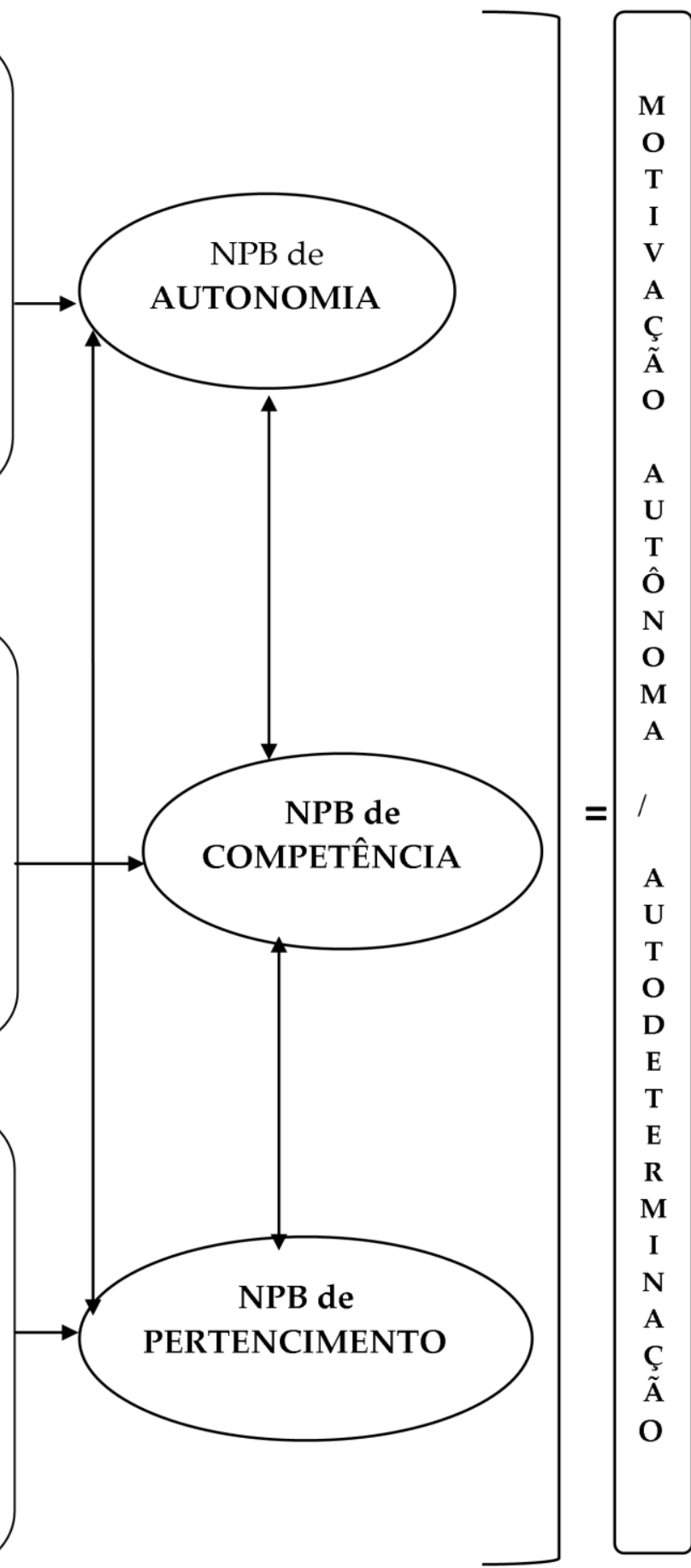

FIGURA 1 - Subcategorias emergentes para a satisfação das NPB dos professores pesquisados que resulta em motivação autônoma

Fonte: As autoras.

(C) ETD-Educação Temática Digital Campinas, SP $\quad$ v.19 $\quad$ n.2 $\quad$ p. 510-531 abr./jun. 2017 
Essas subcategorias descrevem operacionalmente as três NPB, caracterizando os "nutrientes" socioambientais necessários para a sua satisfação, na perspectiva dos professores entrevistados, sendo detalhadas a seguir.

\section{Senso de Autonomia}

Os professores entrevistados apontaram que a satisfação da necessidade psicológica de autonomia na carreira docente é, em grande parte, decorrente da possibilidade de direcionamento da própria trajetória profissional, a partir da sua participação efetiva em decisões cotidianas, como a escolha sobre qual projeto desenvolver, que autores estudar, quais parcerias fortalecer, que conteúdos trabalhar. Pressupõe que quando essas vivências Ihes são permitidas ou estimuladas no meio institucional, o enfrentamento das exigências e dificuldades e a assunção de responsabilidades no contexto acadêmico tendem a ser percebidas como desafios pessoais motivadores, que os direcionam para a busca de novas perspectivas e da própria formação continuada.

Há, portanto, um alinhamento entre esta concepção de autonomia na trajetória docente e a noção de gestão institucional participativa, esta última também emergida no estudo como um dos nutrientes contextuais para a satisfação do senso de autonomia. Para os professores entrevistados a disposição institucional para ver as questões de diferentes pontos de vista, pondo ênfase nos sujeitos e nos elementos humanos, contribui para o desejo pessoal e intrínseco de fazer mais e melhor, conferindo-Ihes a sensação de serem relevantes, por suas características e contribuições, aos processos institucionais. Entende-se que a gestão participativa vem sendo orquestrada de modo mais sistemático na Educação Superior a partir da implementação das políticas e normas do Sistema Nacional de Avaliação da Educação Superior (MINISTÉRIO DA EDUCAÇÃO; SINAES, 2004), tendo em vista que estas políticas demandam pelo envolvimento efetivo de todos os atores do cenário acadêmico (docentes, discentes, colaboradores técnico-administrativos).

Essa percepção de poder decisório do professor em relação ao percurso docente percorrido e sua valorização nos órgãos colegiados impacta, direta ou indiretamente, sobre a subcategoria denominada (re)construção de saberes. O que os professores entrevistados referiram é que o desejo de aprender, aprimorar-se e inovar lhes confere sintonia com a carreira e se instala juntamente com as demandas criadas por suas próprias iniciativas e escolhas, em detrimento à noção de imposição ou metas externas, fortalecendo a percepção de livre-arbítrio associada ao senso de autonomia. O conhecimento e o capital

\section{(c) ETD-Educação Temática Digital Campinas, SP v.19 n.2 p.510-531 abr./jun. 2017}


intelectual genuínos do professor, que se originam das demandas autodeterminadas e se traduzem em confiança na profissão decorreriam, então, de uma construção gradual e voluntária ao longo da própria trajetória docente e não à margem desta.

A flexibilidade no planejamento pedagógico também se coaduna com a noção de autonomia proposta pela SDT, a qual enfatiza o desejo intrínseco ao self de comprometer-se ou realizar algo (RYAN; DECl, 2000). Assim, um planejamento pedagógico com espaço para a interlocução entre possibilidades e demandas, recursos e necessidades, qualificação e interesses tende a despertar no professor maior engajamento e criatividade na realização das atividades. Essa possibilidade de escuta e sincronia com o contexto foi apontada como um dos nutrientes da autonomia na docência, como evidenciou um dos entrevistados:

\begin{abstract}
Sinto possuir autonomia nas disciplinas que leciono para a formação de professores (metodologia, prática de ensino, estágios, TCC, instrumentalização para o ensino) pois não existe o engessamento de conteúdos e é possível trabalhar com as necessidades dos alunos. Quando falo em necessidades dos alunos refirome às aspirações, desejos, inseguranças e críticas que os alunos apresentam à prática docente. (Entrevistado 7).
\end{abstract}

Por outro lado, a subcategoria flexibilidade de horários emergiu especialmente dos professores que atuam na pós-graduação, referindo que a capacidade de produção relacionada à pesquisa independe de tempos e espaços específicos cronometrados, por exemplo, pelo livro/cartão ponto. Ao contrário, o não respeito ao ritmo pessoal de produção de conhecimento, evidenciado no controle externo oposto ao funcionamento autogerido, tenderia a inibir a capacidade produtiva e a motivação para a realização. Não se trata, contudo, de extrapolar normas e limites inerentes ao contrato de trabalho, mas sim de adequar as responsabilidades docentes às características de cada situação, favorecendo a responsabilização pessoal.

Destaca-se que a SDT enfatiza que a autonomia não se refere a ser autossuficiente no sentido de portar-se de forma individualista ou egoísta (RYAN; DECl, 2000). Ao contrário, a pesquisa empírica sobre motivação autodeterminada (por exemplo: KIM; BUTZEL; RYAN, 1998) aponta que a autonomia que fomenta a motivação tende a se reafirmar nas ações voltadas para a coletividade. Os professores do presente estudo confirmaram essa ideia ao apontarem o compartilhamento de experiências com pares como um nutriente para o senso de autonomia, destacando a importância de escutar e ser escutado, tornando-se visível:

(C) ETD-Educação Temática Digital Campinas, SP v.19 n.2 $\quad$ p.510-531 abr./jun. 2017 
Sinto que tenho autonomia quando tenho espaço, momentos para compartilhar com os pares as angústias, os desafios da profissão docente. (Entrevistado 11). Quando sou ouvida pelos colegas quando proponho novas ideias (Entrevistado 14). Sinto autonomia no fato de estar aberta a buscar novas perspectivas, de poder ouvir os colegas que fazem pesquisa e estudam mais do que eu e dividem seus achados nas reuniões de colegiado. (Entrevistado 5).

Identidade/competência profissional consolidada também emergiu como uma subcategoria para a satisfação do senso de autonomia. O modo como os professores se referiram a essa questão, aproximando a noção de autonomia à competência, confirma o pressuposto da SDT de que as NBP são mutuamente interdependentes, de tal modo que a satisfação ou frustração de uma tem reflexos sobre as demais (DECl; RYAN, 2008b).

\footnotetext{
Tenho a sensação que depende de mim a capacidade profissional e essa capacitação gera autonomia. (Entrevistado 4).

Ter autonomia é ter segurança no que se tem certeza, isso quer dizer, na hora de falar, de agir e isso exige conhecimento científico. O conhecimento científico nos proporciona uma base sólida, sustenta-nos para um "poder" no saber. (Entrevistado 10).
}

A atuação em sala de aula foi também considerada responsável pelo senso de autonomia, indicando a relevância para o professor do contato direto com os alunos. Nesse sentido, tanto a desenvoltura e capacidade nos processos de ensinagem/aprendizagem, ligadas ao domínio do conteúdo, como a eficácia/eficiência na transmissão/expressão do conhecimento, relacionadas à transformação do aluno, emergiram como fontes de satisfação da autonomia docente.

Percebo a minha autonomia na minha busca constante por conhecimento a ser repassado de forma contextualizada para o aluno, criando possibilidades para que o aluno se torne um agente de transformação pessoal e por consequência da sociedade. (Entrevistado 19).

Acredito que quando estou em sala de aula diante de uma turma me dá a sensação de autonomia. Afora isto, é difícil ou seria complicado se pensar em autonomia na carreira docente. (Entrevistado 23).

É relevante destacarmos, como já evidenciou a fala do Entrevistado 23, que alguns professores entrevistados expressaram também uma postura crítica ante a noção de autonomia, discorrendo sobre o que se denominou de autonomia ilusória do docente, ao invés de apontarem definições operacionais onde se poderia reconhecer sua autonomia. Assim, em termos motivacionais, as queixas sobre o excesso de demandas, controles de resultados, limitações impostas pelo sistema e expectativas institucionais pelo desempenho

\section{(C) ETD-Educação Temática Digital Campinas, SP v.19 n.2 p.510-531 abr./jun. 2017}


dos alunos depositadas nos professores, sugerem a excessiva frustração ou satisfação parcial e ambivalente dessa NPB.

E se eu não tiver essa sensação de autonomia? Posso pensar que dentro da sala de aula eu tenho uma suposta autonomia, mas muito vigiada pelos alunos e pela própria instituição. (Entrevistado 23).

A autonomia é relativa. Há demandas e exigências superiores, da própria IES e também externas. A docência dá uma ilusão de autonomia em relação à flexibilização do horário, do campo de pesquisa, etc. Mas é ilusão, porque na realidade a dedicação é integral, o tempo todo. (Entrevistado 8).

Com tantas diretrizes, programas, planos e marcos regulatórios tenho clareza de que não possuímos autonomia; mas quando escolho os textos, oriento os temas de estudo e de outras atividades de ensino ou de aprendizagem tenho a sensação de ser autônoma só intelectualmente. (Entrevistado 9).

Segundo a SDT, quando as pessoas se sentem ou são de fato muito vigiadas, ameaçadas ou avaliadas a autonomia fica afetada (DECl; RYAN, 2008b). Como resultado diante disso, ao se considerar o meio ambiente como fornecedor de nutrientes para a qualidade da motivação como propõe a SDT, ao invés de incremento de motivação autorregulada, o que se constata é falta de vitalidade e a baixa energia para o exercício da profissão.

\section{Senso de competência}

O desenvolvimento dos alunos e a interação professor-aluno exitosa ocuparam espaço central na percepção de competência dos professores entrevistados. Com isso fica reforçada a ideia de que o trabalho docente não comporta apenas uma ação instrumental, sendo investido pelas interações interpessoais. Conforme Savater (2012, p. 29) "Na dialética do aprendizado é tão crucial o que sabem aqueles que ensinam quanto o que ainda não sabem os que devem aprender", refletindo-se na noção de eficácia/eficiência docente. Faz sentido, então, a emergência da subcategoria interesse, participação e aprendizagem dos alunos, pois, para esses professores o que os assegura do cumprimento exitoso de sua função se expressa, primeiramente, em manifestações que enfatizem as trocas interpessoais, conforme suas falas:

A participação e a curiosidade dos alunos em minhas aulas. (Entrevistado 1).

A aprendizagem dos alunos e o sentimento de apropriação dos saberes e conhecimentos produzidos. (Entrevistado 3).

Especialmente o "retorno" do acadêmico nas disciplinas, isto é, ele reage positivamente às "provocações" e "desafios" em cada disciplina e semestre. (Entrevistado 23).

\section{(C) ETD-Educação Temática Digital Campinas, SP v.19 n.2 p.510-531 abr./jun. 2017}


Por outro lado, o desempenho dos alunos, não apenas o seu interesse e aprendizagem, foi referido como outro elemento que os professores relacionaram a sua competência, sendo relevantes os resultados tangíveis demonstrados ou obtidos pelos alunos, como por exemplo, notas ou boa execução de tarefas.

Os bons resultados que a maioria dos alunos demonstra na aplicação das diversas estratégias avaliativas. (Entrevista 13).

Percebo que o estudante, de algum modo, aprende os aspectos necessários $\mathrm{p} /$ sua aprovação e mesmo melhoria no desempenho de funções, quando no exercício de atividades na área em que está se formando. Este retorno, às vezes, vem dos próprios empregadores. (Entrevista 21).

Nessa lógica, o professor competente seria também representado e qualificado pelos bons índices de aprovação de seus alunos, implicando que a satisfação dessa NPB não prescinde de certa regulação extrínseca, baseada em resultados externos. Segundo a SDT, porém, essa reciprocidade de elementos intrínsecos e extrínsecos por si só não determina a satisfação ou frustração de uma NPB, sendo fundamental o modo como o sujeito integra esses resultados tangíveis ao self e a percepção de si (DECl; RYAN, 2007).

Outra categoria que emergiu do estudo, refere-se ao feedback positivo recebido pelo professor em relação ao seu trabalho. De acordo com essa subcategoria, a avaliação positiva e o retorno institucional e dos alunos, inclusive no que diz respeito à própria relação interpessoal docente/discente tem relevância para a satisfação do senso de competência:

\footnotetext{
Sinto-me competente com os bons resultados nas avaliações online, efetuada pelos acadêmicos acerca do desenvolvimento de minhas aulas e de meu desempenho docente. (Entrevistado 13).
}

Nota-se, assim, que a motivação autônoma pode ser afetada por eventos sociocontextuais que ocorrem em relação ou durante uma ação, tais como recompensas, feedback e comunicação, como reconhece a SDT (DECl; RYAN, 2000; 2008b). Nessa perspectiva, a competência pode ser também nutrida, segundo os entrevistados, pelo reconhecimento dos alunos, pares e instituição (evidenciado no fato de ser visto como um exemplo/modelo e na forma de convites recebidos, incentivo institucional para qualificação ou inserção na gestão participativa) bem como pelo autorreconhecimento do professor em relação ao próprio trabalho. São, portanto, eventos que impactam sobre o senso de competência:

(C) ETD-Educação Temática Digital Campinas, SP v.19 n.2 $\quad$ p.510-531 abr./jun. 2017 
Os convites que vão surgindo a partir das interações em sala de aula. (Entrevistado 1).

O reconhecimento por parte dos superiores ao ser indicada para determinados cargos ou representações, bem como a própria avaliação dos alunos no retorno das atividades propostas. (Entrevistado 2).

A referência de ex-alunos quando nos encontram e contam situações em que fomos citados como exemplo. (Entrevistado 9).

A qualificação e a formação continuada emergiram também como descritores de competência no exercício da docência por parte dos professores participantes da pesquisa, especialmente quando prepondera o interesse em aprender novas argumentações teóricas e metodológicas, a abertura para o novo, a socialização dos conhecimentos, o manter-se informado, o desejo de qualificação e de inovação do ensino. Assim, quando a formação continuada é aceita como um desafio para a superação das próprias limitações e das demandas da profissão ela assume caráter intrínseco, bastante distinto de quando a qualificação decorre de imposições institucionais ou de expectativas de ganhos externos. 0 impacto disso na competência pode ser observada na fala dos professores:

Em primeiro lugar o desafio constante para me manter atualizada frente aos desafios das novas tecnologias que colocam a disposição cada vez maior quantidade de informações. (Entrevistado 5).

Acho desafiador buscar novas estratégias de aprendizado para melhorar o desempenho e o envolvimento dos alunos. (Entrevistado 21).

Segundo a SDT, porém, exigências intensas por produção, metas impostas sem contextualizações, prazos muito curtos, "ameaças" com recompensas tangíveis e pressão de avaliações tendem a diminuir a sensação de competência, mesmo diante da capacidade técnica e da experiência do professor. A experiência teórico-prática e o domínio do conteúdo foram apontados por vários docentes entrevistados como uma espécie de segurança quanto à competência. Essa segurança não é imediata, mas parece ser adquirida com o tempo, a vivência, a experiência e a afinidade na/com a docência, vindo de encontro com o que afirma Savater (2012, p. 40): “(...) a primeira coisa para educar os outros é ter vivido antes deles, isto é, não o simples ter vivido em geral - é possível e frequente um jovem ensinar coisas a alguém de mais idade-, mas ter vivido antes o conhecimento que se deseja transmitir".

Depois de 40 anos de atividade ainda tenho dúvidas quanto a isso (a minha competência). Acho natural, pois a cada momento os desafios são novos. Há uma constante desestabilização contra a acomodação, natural em qualquer profissão/instituição. (Entrevistado 8).

(C) ETD-Educação Temática Digital Campinas, SP v.19 n.2 $\quad$ p.510-531 abr./jun. 2017 
Por me sentir seguro em lecionar disciplinas, onde consigo repassar experiência acadêmica. Acredito que essas atividades motivam o aluno e transmite segurança para o aluno e professor em sala de aula. (Entrevistado 14).

Para muitos docentes a competência não se dissocia do gosto pela docência, este também evidenciado como um nutriente para a necessidade de competência no exercício da profissão. Os professores se referiram ao compromisso ético e político oriundo da ensinagem (PIMENTA; ANASTASIOU, 2014), o gosto pelo ambiente universitário e pela pesquisa e o empenho visível na flexibilidade, interesse e dedicação para com os alunos, os quais traduzem a ideia de prazer na docência, esta sentida como uma verdadeira escolha ao longo da trajetória profissional, investida de significados subjetivos. Na fala dos professores a competência atrelou-se a essa visão sintonizada e apaixonada da carreira:

[...] gosto de me relacionar com os alunos e ajudá-los no seu processo de formação. (Entrevistado 5).

[...] A minha formação é na pesquisa, mas exerço à docência com paixão e dedicação aos meus alunos. (Entrevistado 20).

Em primeiro lugar, eu gosto da atividade docente. Sinto-me motivada em poder compartilhar o quanto que aprendi e em contribuir para o aprendizado de futuros profissionais da minha área. Em segundo lugar, eu tenho afinidade com as áreas de conhecimento que leciono, o que me motiva a continuar pesquisando e estudando os temas. Em terceiro lugar, tenho afinidades com o trabalho pedagógico. Acho desafiador buscar novas estratégias de aprendizado para melhorar o desempenho e o envolvimento dos alunos. (Entrevistado 21).

Senso de pertencimento

De acordo com os professores pesquisados a sensação de pertencimento ao grupo ou local de trabalho é fomentada e perceptível por meio do reconhecimento pessoal e institucional das lideranças, pares e subordinados, indicado como um descritor para essa NPB. Esse pertencimento se fundamentaria em uma forma de valorização e respeito pelo trabalho realizado e pela função do professor, refletindo-se em inúmeras ações tangíveis: remuneração justa e em dia, estabelecimento de vínculo permanente com a IES, convites para assumir novas responsabilidades, integrar espaços acadêmicos formais ou nas demandas pelo conhecimento do professor através da busca de esclarecimentos pelos alunos, convites para aulas ou palestras.

\section{(C) ETD-Educação Temática Digital Campinas, SP v.19 n.2 p.510-531 abr./jun. 2017}


Há reconhecimento do tempo de pesquisa, pelo apoio e incentivo para produzir conhecimento. Salário, pagamento em dia e reconhecimento institucional são os elementos fundamentais para conferir a sensação de pertencer numa instituição e levar essa confiança em eventos extramuros. Nunca direi a ninguém que reclamações e a sensação de ser excluído não são fatores que podem desmotivar. (Entrevistado 20).

A participação ativa em processos decisórios e em atividades conjuntas, realizadas no contexto acadêmico, coletivamente, de modo formal ou não, emergiu também como um descritor para a satisfação do senso de pertencimento para esses sujeitos. Os professores apontaram grande diversidade de situações coletivas e de interação, quer sejam focadas em tarefas como estudo ou planejamento, ou na simples participação em algum evento, como fundamentais para sentirem bem-estar na experiência de interagirem ou serem notados pelo contexto em que atuam:

Quando partilho ideias, sentimentos e dúvidas. Se participo pouco das reuniões de trabalho onde as decisões são tomadas, neste momento sinto-me um pouco alheia... Assim tenho aquele sentimento de "estrangeiridade". (Entrevistado 9).

Se consigo acompanhar as discussões de grandes temas institucionais; participo ativamente do processo decisório e me posiciono, mesmo não concordando com a maioria. Acredito que ao fazer publicas as minhas posições exerço um importante papel na instituição. (Entrevistado 5).

Quando participo das reuniões de colegiado, tenho abertura para apresentar minhas percepções sobre o curso. Mas, por manter outra atividade além da de docente, por vezes não consigo interagir como gostaria, o que por vezes frustra com relação à integração com a instituição e com o curso. (Entrevistado 14).

Quando percebo o quanto posso desfrutar das habilidades e competências dos meus colegas para qualificar a minha formação. (Entrevistado 25).

Por outro lado, o pertencimento também se materializa em atividades coletivas de caráter não formal, além das situações de trabalho. A convivência social com pares e aceitação de ideias, sentimentos e dúvidas foi apontada pelos professores como ocasiões necessárias para a promoção do pertencimento, identificadas como demonstrações de bem-querer.

Sinto-me pertencente ao grupo quando falamos de projetos comuns de trabalho, trocamos experiências sobre a docência, mas também quando conversamos sobre assuntos pessoais ou familiares. (Entrevistado 25).

Quando o meu conhecimento é recebido e integrado nas discussões do grupo. (Entrevistado 11). 
A satisfação do senso pertencimento, no entanto, é delimitado pelo estabelecimento de relações interpessoais saudáveis, de trocas não contaminadas por excesso de disputas ou impossibilitadas pela falta de tempo.

\begin{abstract}
Sinto-me muito integrada aos meus colegas desde o bom dia receptivo (...), ou no momento de desabafo de frustrações institucionais. Quanto ao contexto docente como um todo tenho parcerias com colegas de outras escolas, mas é uma interação ainda limitada e limitada também com a própria dinâmica institucional porque a demanda é imensa e não tenho tempo hábil para cuidar da vida e não adoecer e cuidar também da vida institucional. (Entrevistado 26).
\end{abstract}

Nesse sentido, as condições de trabalho compatíveis e evidenciaram como outro descritor relevante ao pertencimento. Os professores apontaram que ao serem percebidos como sujeitos e respeitados nos seus diretos e na sua subjetividade há um incremento da noção de pertencimento o que resulta em maior motivação para engajar-se na ação docente.

Sentir-me pertencente implica em ter demandas dosadas, não exigências além das possibilidades (como nos últimos anos!). O tempo para ler, refletir, etc, está cada vez mais reduzido para uma atividade em que isso é condição sine qua non. (Entrevistado 8).

Paralelamente, o desenvolvimento de atividades acadêmicas de qualidade, quer seja no ensino ou na pesquisa, favorecido por condições estruturais e relacionais ofertadas pelo contexto, também contribuem para a satisfação do senso de pertencimento, segundo os entrevistados. Sob a noção de "qualidade" se vislumbra a capacidade crítica docente quanto aquilo que atribui relevância à Educação, em uma perspectiva que beneficie o coletivo, que deve estar em sintonia com o plano político pedagógico, as condições de trabalho, o currículo e as próprias demandas da sociedade.

Essa sensação de ser pertencente que tenho em relação ao contexto docente para mim aflora quando os interesses coletivos se sobrepõem aos interesses pessoais; quando o ensino, o conhecimento exerce o seu papel de ampliação do intelecto da consciência para o bem de toda a humanidade. (Entrevistado 19).

As descrições operacionais do que caracteriza o senso de autonomia, o senso de competência e o senso de pertencimento permitem explorar em que medida o contexto oferece condições (nutrientes) para a satisfação dessas NPB que, em conjunto, impactam na motivação autodeterminada. Contextos promotores de satisfação das NPB tendem a funcionar de modo diverso daqueles que geram insatisfação, ou até mesmo frustração.

(C) ETD-Educação Temática Digital Campinas, SP v.19 n.2 p. 510-531 abr./jun. 2017 
Contudo, não basta apenas considerar o que é ofertado pelo ambiente, sendo necessário haver reciprocidade entre essas ofertas e o que é demandado e internalizado pelo indivíduo, o que posiciona as NPB como protagonistas nas diferenças individuais que acompanham os processos motivacionais. Por exemplo, se um organismo necessita de vitamina B por mais que sejam fornecidos outros complexos vitamínicos, a carência não será suprida e o equilíbrio bioquímico restaurado até que alguma fonte gere a vitamina específica a ser absorvida pelo organismo.

Nessa lógica, as NPB funcionam como um vetorii (ver Figura 2) que permite a interação entre o contexto e as demandas pessoais. Quanto mais ajustada e a assertiva essa interação maior o grau de satisfação das necessidades de autonomia, competência e pertencimento, em um processo cumulativo e somativo, o que se reflete em comportamentos ou funcionamento psicossocial orientados para 0 desenvolvimento/crescimento (expressos por exemplo, em iniciativa, comprometimento, persistência, investimento, criatividade e melhora do desempenho). A ausência de satisfação ou a frustração de qualquer uma das NPB interfere nesse somatório, sendo contabilizadas na forma de maior ou menor motivação autônoma.

Conceitualmente, essa dinâmica é esquematizada na Figura 2 e sugere que a motivação autônoma (denominada também de autodeterminada ou autorregulada) atua como uma espécie de catalisadorii para a vitalidade e o bem-estar do sujeito, o que vem sendo demonstrado empiricamente nos estudos que exploram os pressupostos da SDT nas pesquisas contemporâneas, em diversas áreas do conhecimento, muitas das quais estão agrupadas no sitio específico da SDT ${ }^{\text {iv }}$. Ao catalisar vitalidade e bem-estar, a motivação autônoma tende a tornar-se um importante antídoto para a falta de energia psíquica, o esgotamento físico e o adoecimento dos professores.

(C) ETD-Educação Temática Digital Campinas, SP v.19 n.2 p.510-531 abr./jun. 2017 


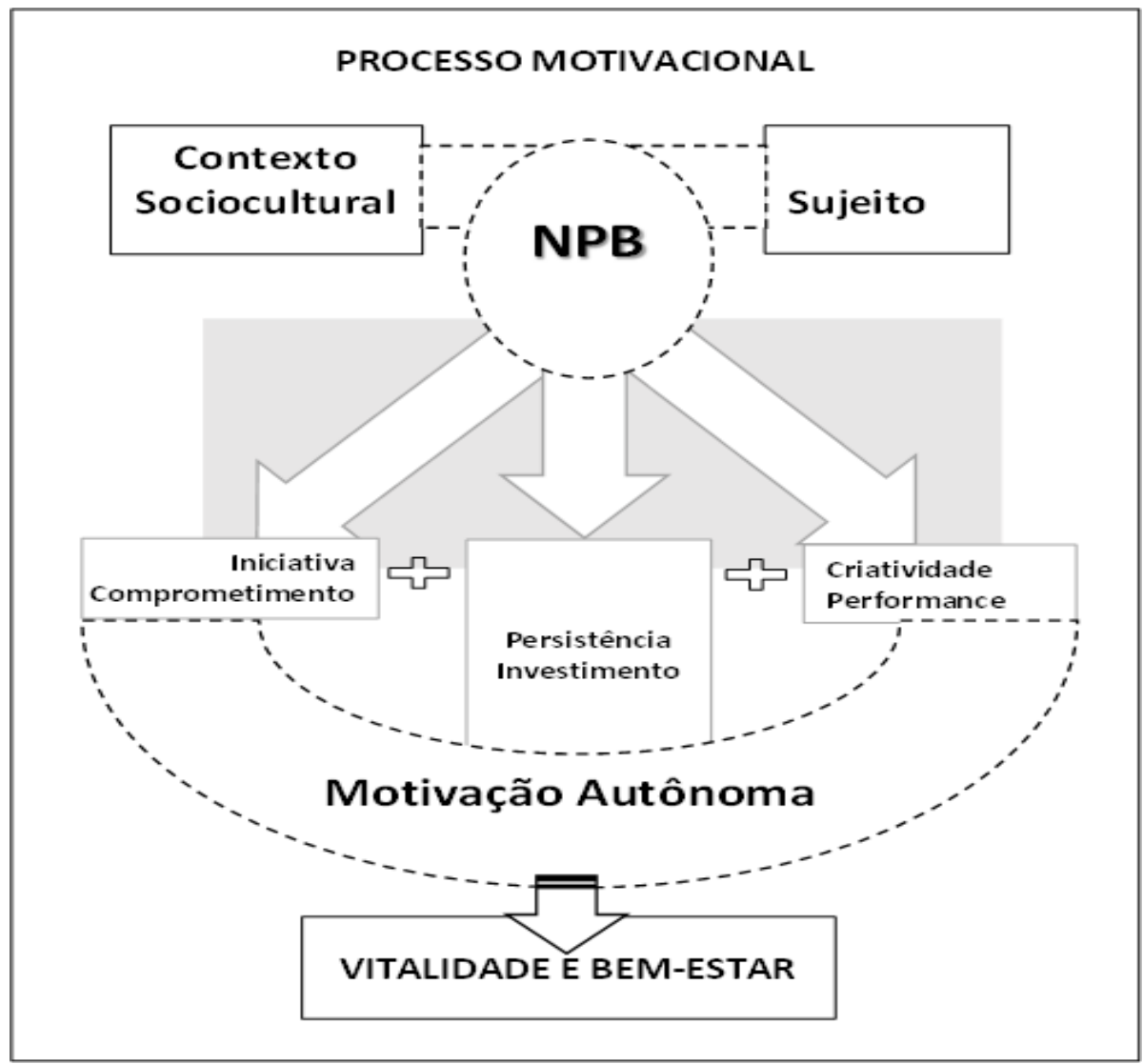

FIGURA 2 - Dinâmica do processo motivacional envolvendo as necessidades psicológicas básicas Fonte: as autoras.

Como afirmam Ryan e Deci (2005), o conhecimento sobre os nutrientes essenciais para a experiência de motivação autônoma e, portanto, para um melhor desempenho e maior bem-estar, tem amplo significado, especialmente no ambiente educacional, pois favorece a assimilação das informações, a internalização de normas e comportamentos adequados, além de facilitar o comprometimento com as tarefas e metas. Acreditamos que na medida em que melhor se conhece a dinâmica subjacente à motivação autônoma, muito vinculada aos contextos em que se manifesta, torna-se também mais factível a pesquisa experimental sobre o construto, tendo em vista que na atualidade a maior parte das pesquisas sobre a motivação centra-se em desenhos correlacionais. Com isso, amplia-se também a possibilidade de explorar os mecanismos que operam na mudança motivacional e desenvolver intervenções voltadas a esse propósito.

\section{(c) ETD-Educação Temática Digital Campinas, SP v.19 n.2 p.510-531 abr./jun. 2017}




\section{CONSIDERAÇÕES FINAIS}

As dezenove subcategorias que emergiram das respostas dos professores entrevistados configuraram-se como descritores operacionais para as NPB, estas últimas aqui consideradas, do ponto de vista metodológico, como as categorias previamente definidas: Autonomia, Competência e Pertencimento. Partindo da noção de motivação intrínseca, na qual a motivação para uma ação se fundamenta na própria ação, sentida como recompensadora ou produtora de satisfação pessoal, a SDT enfatiza que o contexto sociocultural tem influência sobre a qualidade da motivação que orienta o sujeito, ou seja, se é mais ou é menos autorregulada pelo próprio self (autônoma).

Portanto, conhecer a percepção dos docentes universitários acerca do que nomeiam como Autonomia, Competência e Pertencimento mostra-se um passo importante para impulsionar a produção de conhecimento sobre os processos motivacionais, servindo de subsídio para novos estudos, inclusive de natureza quantitativa, por meio de instrumentos específicos que capturem as NPB. Note-se, por exemplo, que a noção de autonomia foi polêmica nos resultados encontrados, apresentada na forma de uma subcategoria crítica "independente", remetendo ao importante debate contemporâneo acerca da precarização da docência, merecendo maior atenção em pesquisas futuras sobre as NPB. Além disso, a definição operacional das NPB tem especial importância no desenvolvimento de instrumentos e medidas para serem utilizados em pesquisas empíricas voltadas para a exploração e mensuração da motivação autônoma, abrindo um vasto campo para estudos futuros.

Por outro lado, as implicações do estudo podem ainda se refletir nas políticas institucionais para a qualificação da ação docente e, consequentemente, da Educação Superior, tendo reflexos na própria qualidade de vida do sujeito professor. Políticas institucionais ou públicas que levem em conta o bem-estar e a vitalidade do docente se alinham com a construção do fortalecimento e expansão da carreira docente.

Ressaltamos, contudo, que os resultados apresentados são incipientes e localizados, necessitando de aprofundamento de pesquisas, comparando-os a outros cenários docentes a fim de formar um escopo consistente e representativo desses descritores.

\section{(c) ETD-Educação Temática Digital Campinas, SP v.19 n.2 p.510-531 abr./jun. 2017}




\section{REFERÊNCIAS}

BIANCHETTI, Lucídio; MACHADO, Ana Maria Netto. Trabalho docente no stricto sensu: publicar ou morrer?!. In: FIDALGO, Fernando; OLIVEIRA, Maria Auxiliadora Monteiro; FIDALGO, Nara Luciene Rocha (Org.). A intensificação do trabalho docente: tecnologias e produtividade. Campinas, SP: Papirus, 2013, p. 49-89.

BRASIL. Lei n.10.861 de 15 de abril de 2004. Institui o Sistema Nacional de Avaliação da Educação Superior - SINAES e dá outras providências. Brasília, SP: MEC, 2004. Disponível em: http://goo.gl/T7v7HI. Acesso em: 04 abr. 2016.

CAMPOS, Casemiro de Medeiros. Saberes docentes e autonomia dos professores.

Petrópolis, RJ: Vozes, 2007. 104 p. Disponível em: http://goo.gl/GdSOdc. Acesso em: 04 abr. 2016.

DECl, Edward L.; RYAN, Richard. M. Self-determination theory: a macrotheory of human motivation, development, and health. Canadian Psychology, v. 49, n. 03, p. 182-185. ago. 2008. Acesso em: 14 mar. 2016. ISSN 0708-5591.

DECI, Edward L.; RYAN, Richard M. Facilitating optimal motivation and psychological wellbeing across life's domains. Canadian Psychology, v. 49, n. 01, p. 14-23. fev. 2008. Disponível em: http://goo.gl/FhTrBD. Acesso em: 14 mar. 2016. ISSN 0708-5591.

DECl, Edward L.; RYAN, Richard M. Active human nature: self-determination theory and the promotion and maintenance of sport, exercise and health. In: HAGGER, Martin; CHAZISARANIS, Nikos (Eds.). Intrinsic motivation and self-determination in exercise and sport. Champaign, Illinois: Human Kinetics, 2007, p. 03-16. Disponível em: http://goo.gl/hduqiN. Acesso em: 04 abr. 2016.

DECl, Edward L.; RYAN, Richard M. The "What" and "Why" of goal pursuits: human needs and the self-determination of behavior. Psychological Inquiry, 2000, v. 11, n. 04, p. 227268. Disponível em: http://goo.gl/cvu9Ek. Acesso em: 04 abr. 2016. ISSN 1532-7965.

JESUS, Saul Neves de; SANTOS, Joana Conduto Vieira. Desenvolvimento profissional e motivação dos professores. Educação, Porto Alegre, RS, v. 52, n. 01, p. 39-58. jan./abr. 2004. Disponível em: http://goo.gl/WldyVF. Acesso em: 21 mar. 2016. ISSN 1981-2582. 
KIM, Youngmee; BUTZEL, Jessica Solky; RYAN, Richard M. Interdependence and well-being: a function of culture and relatedness needs. Saratoga Spring/NY: Paper presented at The International Society for the Study of Personal Relationships. jun. 1998.

MOROSINI, Marília Costa. Docência universitária e os desafios da realidade nacional. In: MOROSINI, Marília Costa (Org.). Professor do ensino superior: identidade, docência e formação. Brasília, DF: INEP, 2000. p. 11-20. Disponível em: http://goo.gl/BiXUw5. Acesso em: 04 abr. 2016.

MORAES, Roque; GALIAZZI, Maria do Carmo. Análise textual discursiva. 2. ed. Ijuí, RS: UNIJUÍ, 2013. 224 p. Disponível em: http://goo.gl/39TC5I. Acesso em: 04 abr. 2016.

PASQUALI, Luiz. Instrumentação psicológica: fundamentos e prática. Porto Alegre, RS: Artmed, 568 p. 2010. Disponível em: http://goo.gl/vrJk7g. Acesso em: 04 abr. 2016.

PIMENTA, Selma Garrido; ANASTASIOU, Léa das Graças Camargos. Do ensinar à ensinagem. In: PIMENTA, Selma Garrido; ANASTASIOU, Léa das Graças Camargos. Docência no ensino superior. São Paulo, SP: Cortez. 5. ed.. p. 201-243. 2014. Disponível em:

http://goo.gl/Eg27BE. Acesso em: 04 abr. 2016.

RYAN, Richard. M.; DECl, Edward L. Overview of self-determination theory: an organismic dialectical perspective. In: DECl, Edward L.; RYAN, Richard. M. (Eds.). Handbook of selfdetermination research. Rochester, NY: University of Rochester Press. p. 03-33. 2002 Disponível em: http://goo.gl/70gP4A. Acesso em: 04 abr. 2016.

RYAN, Richard M; DECl, Edward L. Self-determination theory and the facilitation of intrinsic motivation, social development, and well-being. American Psychologist, v. 55, n. 01, p. 6878. 2000. Disponível em: http://goo.gl/fDXbkT. Acesso em: 14 mar. 2016. ISSN 0003-066X.

SANTOS, Bettina Steren dos; RODENBUSCH, Camila de Barros; ANTUNES, Denise Dalpiaz. Aspectos motivacionais da profissão docente universitária. ETD - Educação Temática Digital, Campinas, SP, v. 10, n. especial, p. 294-312. out. 2009. Disponível em: http://goo.gl/w9vxuS. Acesso em: 23 mar. 2016. ISSN 1676-2592.

SAVATER, Fernando. $O$ valor de Educar. 2. ed. São Paulo, SP: Planeta. 224 p. 2012. Disponível em: http://goo.gl/2zapbw. Acesso em: 04 abr. 2016.

SOARES, Sandra Regina; CUNHA, Maria Isabel da Cunha. Formação do professor: a docência universitária em busca de legitimidade. Salvador, BA: EDUFBA, 132 p. 2010. Disponível em: http://goo.gl/8m1ToX. Acesso em: 04 abr. 2016.

\section{(C) ETD-Educação Temática Digital Campinas, SP v.19 n.2 p.510-531 abr./jun. 2017}


VISEU, João N.; JESUS, Saul Neves de; QUEVEDO-BLASCO, Raúl; RUS, Claudia L.; CANAVARRO, José M. Motivação docente: estudo bibliométrico da relação com variáveis individuais, organizacionais e atitudes laborais. Revista Latinoamericana de Psicologia, v. 47, n. 01, p. 58-65. 2015. Disponível em: http://goo.gl/k8EJvH. Acesso em 23 mar. 2016. ISSN 0120-0534.

\title{
AGRADECIMENTOS
}

Nossos agradecimentos pelo fomento à pesquisa para a Fundação de Amparo à Pesquisa do Rio Grande do Sul (FAPERGS), à CAPES e ao CNPq.

\footnotetext{
' Conceitualmente, uma equação representa uma frase matemática, na qual há presença de pelo menos uma incógnita, que expressa uma igualdade, ou seja, o equilíbrio entre os termos. Neste caso, essa(s) incógnita(s) pode $(\mathrm{m})$ ser compreendida(s) como descritor(es) operacional(ais) (subcategorias) e/ou o grau de satisfação de cada um destes.

ii Vetor é um termo aplicado a diferentes áreas do conhecimento, tais como a Química, a Física, a Epidemiologia para referir o meio condutor, um agente de disseminação.

iii $O$ termo catalisador está sendo empregado em referência aos princípios do processo de catalisação oriundo da Química, pretendendo caracterizar um elemento que apresenta a propriedade de aumentar a velocidade/intensidade de uma reação, acelerando os seus efeitos desejáveis ou retardando os indesejáveis.

iv A SDT mantém o sitio http://goo.gl/bcQLxk, no qual estão compiladas inúmeras publicações de diferentes áreas do conhecimento, fundamentadas nessa teoria.
}

Revisão gramatical do texto sob a responsabilidade da equipe da revista ETD

\author{
(C) ETD-Educação Temática Digital Campinas, SP v.19 n.2 p. 510-531 abr./jun. 2017
}

